\title{
Sao Paulo
}

National Cancer Institute

\section{Source}

National Cancer Institute. Sao Paulo. NCI Thesaurus. Code C156338.

A state in the Southeast Region of Brazil. Its capital is Sao Paulo. 